of temperature. The depth of eight leet gave the smallest amount of material to resist these combinel factors of strain.

In regard to the stiflness of our bridge, which you seem to doubt, we wonld most respectfully refer you to page 38 of the Appendix to Capt. Fads' Report, where the vertical defection of the rib under the most disalvantageous distribution of the load is calculated as not exceding $2 \cdot 69$ inches, and the greatest horizontal deflection $0 \cdot 8$ inches.

Your objection in regart to the omission of spandril bracing, becomes nugatory if, as we think we have shown, the rib possesses sufficient stiffincss in itself.

Very respectully, your obedient servant, (Signed),

IIENRY FLat, Chas. Pfeifir,

\title{
THE STREET TUNNEL AT CHICAGO AND ITS MACHINERY,
}

By Prot. S. W. Rominson, C. E.

A $\mathrm{T}$ the time of my visit to the Chicago Washington Street Tunnel, on the 13th inst, the work of tunneling under the river was considerably more than half completed. The approach and arched way on one side are entirely finished as far as to the centre of the river, and work has begun briskly on the opposite bank.

The bed of the river consists of soft, tough clay. It is therefore impracticable, if' not impossible, to drive the tunnel without unroofing it, especially under the river's bed. And as it is necessary to continue the work without interrupting the river navigation, and still uncover the roof, it became necessary to establish a coffer-dam that should extend to only about half of the river's breadth at one time. By means of such a dam, the tunnel has been completed up to the centre of the river, and covered again. The dam was then transferred to the opposite shore, shifting at the same time the passage for boats.

The second dam was completed on the 13 th inst., and the water partly withdrawn with the pumps still working. Two pumps were in operation ; a rotary and a vacuum pump. The latter is of new design, and deserves more particular mention. It will directly be more fully described. The work of uncovering the tunnel bed has begun on this side just beyond the dam, or river bank, and pro. ceeded to a deptl of fifty feet, with about the same length and 
breadth. When the coffer-dam is emptied, the excavation will be extended into it, and the finished part of the arching brought for. ward beyond the limits of the river and covered. The dam can then be removed from the river entirely, and the tunnel continued to its second approach.

Two power derricks are in use for hoisting and shifting the excavated material, only a part of which is required to be taken away, viz.: a volume equal to that of the tumnel, the approaches and the masonry. The balance is to be transferred from its native bed to the top of the tumnel. In doing this, the derricks command about a cubic yard at a lift, which is raised at the rate of a foot per second, taking and depositing it albout forty-five feet from the centre mast.

The clay is so soft that the sides of the excavation must be supported to protect the foundations of adjacent buildings. This is effected by means of cross timbers pressing against plank walls. The clay is handled with hay forks, it being previously cut into lumps with sharp spades. It was noticeable that the workmen were very careful to entirely free every lump, that it should not be found tied down by the tenacity of a small unsevered fragment. On the whole, the work appeared to be progressing very favorably, with a good prospect of a speedy and successful termination.

The vacuum pump spoken of above, is simple and, it is said, very efficient. It consists of a cylindrical chamber of wood, strongly hooped, being about three and a half feet in diameter, and about five feet in height; having suction and discharge pipes with valves properly arranged, and a steam pipe leading from a boiler; together with a small injector vessel supplied with water. Steam of the desired pressure is forced into the chamber by the steam pipe, when the admission is arrested by a three-way valve, a branch pipe leading therefrom, terminated by a check valve, allows the escape of steam from the chamber until the pressure of the atmosphere is reached. As soon as this occurs, a valve drops in the vessel upon the top of the chamber, introducing a spray jet, by whieh the remaining stream is condensed, thus forming the vacuum. The valve of the suction pipe is then raised, and water rushes in from below and fills the chamber. This done, steam is again forced into the same chamber in contact with the water, which promptly retires before it through the discharge pipe. The small injector vessel is filled with water from the discharge pipe. When the water 
is driven out, the three-way valve checks the steam, and the vacuum is again formed, and the above described operations repeated, which may be so continned indefinitely. The three-way valve was operated by a person stationed for that purpose. The water was raised about twelve feet, to be discharged over the dam. By a similar machine, it is sail water has been raised in a jet to a height of over 100 feet.

A question is naturally raised as to whether this is an economi. cal method of using steam. Let us consider this subject briefly. It was ascertained by actual observation with thermometers, that the water discharged over the dam by this pump, was increased in temperature two degrees. By calculation it is determined that the condensation of the steam remaining in the chamber at atmospheric pressure, is sufficient to raise the temperature of the chamber full of water about two-thirds of a degree. There is then imparted one and one-third degrees of heat to the water by reason of the admission of steam to contact with it, and with the wet interior surface of the chamber. The prejudicial result effected by operating this contrivance, is then represented by the mechanical effect equivalent to heating all the water discharged one and one-third degrees. It was determined by Joule and Maycr, independently, that to raise the temperature of one pound of water one degree, requires a mechanical effect equal to raising 772 pounds one foot high. The volume discharged per minutc, at the rate of three strokes, is $144 \cdot 3$ cubic feet, or 9018.7 pounds. To raise this twelve feet per minute, requires three and three-tenths horse-power. But to heat it one and one-third degrees, requires per minute, a mechanical effect equal to $9018.7 \times 7 \% 2 \times 1_{3}^{1}=9280244^{\circ} \mathrm{ft}$. pounds $=281$ horsepower, But the steam was all taken from a fifteen or twenty horse boiler. What, then, is the mechanical equivalent in this case?

But let us take another view of the case. To heat a given quantity of water one and one-third degrees, takes twice as much steam as to heat it two-thirds of a degree. Then if $144 \cdot 3$ cubic feet of steam, at atmospheric pressure, will heat the same volume of water, at the ordinary temperature, two-thirds of a degree twice the quantity of steam at atmospheric pressure will raise the temperature of $144 \cdot 3$ cubic feet of water one and one-third degrees. If the last named quantity of sterm, which is the amount lost by incidental condensation, be used each minute in a steam cylinder at sixty pounds apparent pressiure, it would perform the work of two and 
a half horses. Taking this as the prejudicial work of the vacuum pump, and $3 \cdot 3$ horse-power, which was shown above to be the theoretical work required to raise the water, we find that the work lost is 0.76 of the useful effect; and 0.43 of the total effect; which is a large per centage for even ordinary pumps. If this is true, it appears from the results of the experiments cited, that as a device for raising water, the vacuum pump is not an economical machine, except where convenience demands its use, or where its temporary employment justifies the application in preference to more costly machinery.

One of the most essential pre-requisites for economical results with this device, is, that the surfaces with which the steam and water have alternate contact, must be non-conductors of heat. Indeed, the measure of success depends upon the degree to which this principle attains. One might at first naturally suppose that the cold water surface would contribute to rapid condensation of steam. But it is very well known in the science of physics, that water is one of the poorest conductors of heat; which becomes particularly apparent in the downward direction where conviction fails to act. A remarkable statement, substantiating this fact, on a large scale, appeared in the Scientific American, early last spring, in which it was confidently asserted that one of two boilers of moderate size, established in separate arches, connected by a steam pipe having no separating valve, had frequently been fired while the other was not, although still containing the ordinary supply of water; and that the water in the unfired boiler had not changed materially in temperature after a considerable interval of time. From this, together with the facts relating to the vacuum pump, it appears that water is a poorer conductor of heat than the wet wood of the inte. rior of the chamber, as the amount of condensation incident upon the ejection of water is very considerable. If so poor a conductor as wood is barely suitable for the interior of the chamber, iron could not possibly answer, notwithstanding the want of its strength to guard against explosion; although iron cylinders lined with wood or other non-conducting material, might serve the purpose well, some good non-conducting material having little inclination to retain water, as wet would form the best lining. That so good a conductor as iron cannot form the interior surface, is strikingly shown by the performance of certain surface condensers. In Hamilton, Ontario, at the machine works of the Northey Brothers, a twelve

Vol. LVII.-ThIRD SkRIES.-No. 1.-JANUARY, 1869. 
horse engine exhausts into a cylindrical wrought iron chamber about two and a half feet in diameter, and thirty feet high. It is of boiler plate, about five-sixteenths of an inch thick. A stream of water delivered upon the top flows down over the whole exterior surface. This chamber maintains nearly a perfect vacuum.

University of Michigan.

S. W. RoBIyson.

\section{THE ECONOMICAL CONSTRUCTION OF BEAM TRUSSES.}

BY G. S. Morison, C. E.

(Connluded from page 399.-Vol. LVI.)

\section{Case of Four Continuous Spans.}

THE two central spans are supposed equal, and each one-quarter larger than the end spans, and as such a bridge is perfectly symmetrical, only the first two spans need be examined. The truss is supposed to be a Warren girder, single system, arranged for a through bridge, the floor being supported on the bottom chord at he end of each panel, and hung by a vertical tie from the upper chord at the panel centres. The depth of truss is taken at thirty feet, and the length of panel the same; the number of panels in the end spans sixteen, and in the central spans twenty, making the length of these spans respectively, 240 and $\mathbf{3 0 0}$ feet. The dead load is assumed to be 1,000 pounds per foot, and the moving load 1,500; making for the bridge of two trusses a total load of 5,000 pounds per foot. This form of truss is selected on account of its simpli. city, an equal amount of weight being thrown upon the truss at the intersection of each brace with either chord.

Representing the chord strains at the five points of support by $s_{1} s_{2} s_{3} s_{4}$ and $s_{5}$, the lengths of the four spans by $l_{1} l_{2} l_{3}$ and $l_{4}$, and their respective loads per foot by $w_{1} w_{2} w_{3}$ and $w_{4}$, we have-

$$
l_{2}=l_{3}=1 \cdot 25 l_{1}=1 \cdot 25 l_{4}=1 \cdot 25 l, \mathrm{~s}_{1}=0 \mathrm{~s}_{5}=0
$$

and equation (6) gives-

$$
\begin{aligned}
& 18 \mathrm{~s}_{2}+5 \mathrm{~s}_{3}+\frac{l^{2}}{h} w_{1}+1.953125 \frac{l^{2}}{h} w_{2}=0 \\
& 5 s_{2}+20 s_{3}+5 s_{4} \\
& +1.953125 \frac{l^{2}}{h} w_{2}+1.953125 \frac{l^{2}}{h} w_{3}=0 \\
& 5 \mathrm{~s}_{3}+18 \mathrm{~s}_{4} \\
& +1.953125 \frac{l_{2}}{h} w_{3}+\frac{l^{2}}{h} w_{4}=0
\end{aligned}
$$

